\title{
Hypertension and Acute Mountain Sickness in Himalayan Trekkers in Nepal: An Observational Cohort Study
}

\author{
Charles B. Duke, MD, $\mathrm{PhD}^{1}$; T. Douglas Sallade, $\mathrm{DO}^{2}$; Jennifer Starling, $\mathrm{MD}^{3}$; Sushil Pant, $\mathrm{MD}^{4}$; Alison Sheets, $\mathrm{MD}^{5}$; \\ Matthew K. McElwee, MD, $\mathrm{PhD}^{6}$; David S. Young, $\mathrm{MD}^{7}$; Richard Andrew Taylor, $\mathrm{MD}^{1}$; Linda E. Keyes, $\mathrm{MD}^{8}$ \\ ${ }^{1}$ Department of Emergency Medicine, Yale School of Medicine, New Haven, CT; ${ }^{2}$ Department of Emergency Medicine, Geisinger Medical Center, \\ Danville, PA; ${ }^{3}$ Department of Emergency Medicine, University of Colorado and Colorado Permanente Medical Group, Saint Joseph Hospital, Denver, \\ CO $;{ }^{4}$ Mountain Medicine Society of Nepal, Kathmandu, Nepal; ${ }^{5}$ Boulder Emergency Physicians, Boulder, CO; ${ }^{6}$ Department of Medicine, Division of \\ Rheumatic and Autoimmune Diseases, University of Minnesota, Minneapolis, MN; ${ }^{7}$ Department of Emergency Medicine, University of Colorado School \\ of Medicine, Aurora, CO; ${ }^{8}$ University of Colorado Emergency Medicine and Boulder Emergency Physicians, Boulder, CO
}

\begin{abstract}
Introduction-A history of preexisting hypertension is common in people participating in mountain activities; however, the relationship between blood pressure (BP), preexisting hypertension, and acute mountain sickness (AMS) is not well studied. We sought to determine these relationships among trekkers in the Everest region of Nepal.

Methods - This was a prospective observational cohort study of a convenience sample of adult, nonpregnant volunteers trekking in the Everest Base Camp region in Nepal. We recorded Lake Louise Scores for AMS and measured BP at $2860 \mathrm{~m}, 3400 \mathrm{~m}$, and $4300 \mathrm{~m}$. The primary outcome was AMS.

Results - A total of 672 trekkers (including 60 with history of preexisting hypertension) were enrolled at $2860 \mathrm{~m}$. We retained 529 at $3400 \mathrm{~m}$ and 363 at $4300 \mathrm{~m}$. At $3400 \mathrm{~m}, 11 \%$ of participants had AMS, and $13 \%$ had AMS at $4300 \mathrm{~m}$. We found no relationship between AMS and measured BP values $(P>0.05)$, nor was there any relation of BP to AMS severity as measured by higher Lake Louise Scores $(P>0.05)$. Preexisting hypertension (odds ratio [OR] 0.16; 95\% CI 0.025-0.57), male sex (OR 0.59; 95\% CI 0.37-0.96), and increased $\mathrm{SpO}_{2}(\mathrm{OR} 0.93 ; 95 \%$ CI $0.87-0.98)$ were associated with reduced rates of AMS in multivariate analyses adjusting for known risk factors for AMS.

Conclusions-AMS is common in trekkers in Nepal, even at $3400 \mathrm{~m}$. There is no relationship between measured BP and AMS. However, a medical history of hypertension may be associated with a lower risk of AMS. More work is needed to confirm this novel finding.
\end{abstract}

Keywords: acclimatization, altitude, BP, travel, hypoxia, risk factors

\section{Introduction}

Acute mountain sickness (AMS), caused by rapid exposure to high altitude and resultant hypoxemic stress, is a common condition among people participating in mountain activities and may progress to life-threatening illness. The

Part of this work has been presented in abstract form at the 2015 Hypoxia Symposia in Lake Louise, Canada, and the 2016 International Society for Mountain Medicine and Wilderness Medical Society joint meeting in Telluride, $\mathrm{CO}$

Corresponding author: Linda E. Keyes, MD, University of Colorado Emergency Medicine, Attending Physician, Boulder Emergency Physicians, Boulder, CO 06510; e-mail: linda.keyes@ aya.yale.edu.

Submitted for publication April 2019.

Accepted for publication January 2020. pathophysiology of AMS is complex and involves, among other things, changes in cerebral blood flow (CBF), oxygen delivery, and vasodilation-all physiologic responses that may also be affected by both acute or chronic blood pressure (BP) changes. Although BP is known to vary with changes in altitude ${ }^{1}$ and hypertension is a common chronic condition in people participating in mountain activities, ${ }^{2-4}$ the relationship among acute BP values, chronic hypertension, and altitude-related illnesses is not well understood.

People with hypertension frequently consult their physicians about the safety of travel to high altitude, but clinicians lack evidence to guide recommendations. ${ }^{5}$ Prior studies examining $\mathrm{BP}$, preexisting hypertension, and 
AMS are limited and often report conflicting results. In 1 prior study of travelers to Summit County, Colorado, the prevalence of AMS was not different in those with hypertension versus those without. ${ }^{6}$ By contrast, in a hypobaric chamber study of men with borderline elevated BP and a family history of hypertension, 8 of 18 developed AMS versus 0 of 15 normotensive men with no family history of hypertension, suggesting a different susceptibility to AMS. $^{7}$ These studies were restricted by focus on travelers at moderate altitudes $(<3000 \mathrm{~m})$ or were performed in the laboratory setting and may not be applicable to trekkers at higher altitudes. A more recent study found no difference in occurrence of AMS in those with preexisting hypertension versus those without, but AMS was not evaluated contemporaneously with $\mathrm{BP}$, and the study included participants with a wide range of ascent rates, maximum altitudes, and geographic locations, introducing several sources of bias. ${ }^{8}$ Further research is thus warranted to determine the risks of travel to high altitude for people with preexisting hypertension and to better understand the association of BP changes with AMS. ${ }^{5}$

In the current study, our objectives were to determine 1) the current prevalence of AMS at 2 altitudes in the Everest region of Nepal; 2) whether a relationship existed between trekkers' measured BP values and the occurrence of AMS; and 3) whether a diagnosis of preexisting hypertension with its attendant chronic vascular changes was a risk factor for AMS when controlling for other previously documented risk factors.

\section{Methods}

\section{STUDY SETTING}

This was a prospective observational study of trekkers at $2860 \mathrm{~m}, 3400 \mathrm{~m}$, and $4300 \mathrm{~m}$ in the Solukhumbu Valley of Nepal from October 8, 2014 through November 2, 2014. The Nepal Health Research Council ethics board approved this study.

\section{STUDY POPULATION}

This was a convenience sample of trekkers who were recruited after arrival by air to Lukla, Nepal, at $2860 \mathrm{~m}$ on the trail outside the airport or in nearby tea houses. Trekkers were excluded if they were pregnant, were aged $<18 \mathrm{y}$, or did not speak English. Written informed consent was obtained from all participants.

\section{STUDY DESIGN AND OUTCOME MEASURES}

This was a prospective observational study and conforms to the strengthening the reporting of observational studies in epidemiology statement guidelines. ${ }^{9}$ Details of the study design and subject questionnaire have been reported elsewhere. ${ }^{1,2}$ Briefly, participants were administered a written questionnaire for demographic data, past and current medical history including history of hypertension, and current medications. We measured physiological variables at $2860 \mathrm{~m}, 3400 \mathrm{~m}$, and $4300 \mathrm{~m}$. For each participant, BP was measured by medically trained study volunteers using manual cuffs (Welch Allyn). Participants were in a seated position with both feet on the ground for at least 5 min before each measurement. BP was measured on the same arm at each altitude. $\mathrm{SpO}_{2}$ and heart rate data were collected using Contec CM550D pulse oximeters, also while participants were seated for at least $5 \mathrm{~min}$ at rest with a steady waveform noted. The Lake Louise Score (LLS) for AMS was assessed by written questionnaire at $3400 \mathrm{~m}$ and $4300 \mathrm{~m}$.

The primary outcome was AMS as defined by an LLS $\geq 3$ with headache. ${ }^{10}$ To compare those with and without underlying hypertension, we defined the "preexisting hypertension" group as participants who self-reported a history of hypertension on our questionnaire by checking a block labeled "yes" for medical history of high BP (hypertension) among a list of other medical conditions such as diabetes and asthma. If they selected yes, participants were also asked specifically what medicine they took for their high BP.

\section{STATISTICAL ANALYSIS}

Data collected on paper questionnaires were transcribed to Microsoft Excel and Google Sheets spreadsheets for data analyses. Descriptive statistics were calculated in Microsoft Excel and are presented as mean $(95 \% \mathrm{CI})$ or frequency.

We conducted univariate and multivariate logistic regression models to examine the association among AMS, measured BP, and preexisting hypertension. Additional variable selection for the model was determined by expert consensus; guided by previously reported risk factors of AMS (age, sex, body mass index [BMI], acetazolamide use, ibuprofen use, and $\left.\mathrm{SpO}_{2}\right)^{11-13}$; and restricted by adherence to the recommended 10:1 ratio of outcomes to variables to guard against overfitting. Rate of ascent was excluded as a variable from the analysis owing to a uniform ascent rate across all participants (Table 1). Missing data in the multivariate logistic model were imputed using random forest imputation (rfImpute, $\mathrm{R}$ randomForest package). We used the Hosmer-Lemeshow goodness-of-fit test to assess overall model performance for AMS and calculated the area under the receiver operating characteristic curve to test the discrimination in this model for the same outcome. Multicollinearity was checked by variance inflation factor, and influential variables and outliers were checked by Cook's distance. All analyses were performed using Excel and R statistical software (v 3.1.1). 
Table 1. Acute mountain sickness and risk factors at $3400 \mathrm{~m}$ and $4300 \mathrm{~m}$

\begin{tabular}{|c|c|c|c|c|}
\hline \multirow[t]{2}{*}{ Variable } & \multicolumn{2}{|c|}{ No AMS } & \multicolumn{2}{|c|}{$A M S$} \\
\hline & $3400 \mathrm{~m}$ & $4300 \mathrm{~m}$ & $3400 \mathrm{~m}$ & $4300 \mathrm{~m}$ \\
\hline $\mathrm{n}(\%)$ & $472(89)$ & $315(87)$ & $56(11)$ & $48(13)$ \\
\hline Male, n (\%) & $284(60)$ & $193(61)$ & $25(45)^{\mathrm{a}}$ & $24(50)$ \\
\hline SBP (mm Hg) & $128(118-138)$ & $128(118-138)$ & $128(116-138)$ & $128(118-139)$ \\
\hline $\mathrm{DBP}(\mathrm{mm} \mathrm{Hg})$ & $82(81-83)$ & $83(82-84)$ & $82(80-84)$ & $84(81-86)$ \\
\hline HR (beats $\cdot \min ^{-1}$ ) & $84(82-85)$ & $82(80-83)$ & $87(84-90)$ & $86(82-89)$ \\
\hline $\mathrm{SpO}_{2}(\%)$ & $90(88-93)$ & $87(84-89)$ & $90(88-92)$ & $85(81-88)^{b}$ \\
\hline Preexisting hypertension, n (\%) & $41(98)$ & $24(96)$ & $1(2)^{c}$ & $1(2)$ \\
\hline Acetazolamide, n (\%) & $61(13)$ & $49(16)$ & $6(11)$ & $8(16)$ \\
\hline Ibuprofen, $\mathrm{n}(\%)$ & $28(6)$ & $19(6)$ & $6(11)$ & $5(10)$ \\
\hline Mean rate of ascent (range) (nights) & $1(0-3)$ & $3(1-5)$ & $1(0-3)$ & $3(1-5)$ \\
\hline
\end{tabular}

Values are means (95\% confidence intervals) unless noted otherwise.

${ }^{\mathrm{a}}$ Lower vs women $(P=0.03)$.

${ }^{\mathrm{b}}$ Lower in those with acute mountain sickness $(P=0.02)$.

${ }^{\mathrm{c}}$ Lower vs participants without preexisting hypertension $(P=0.04)$.

Our study had $80 \%$ power to detect a $20 \%$ difference in the frequency of AMS between those with and without preexisting hypertension using a conservative estimate of a $10 \%$ baseline rate of AMS.

\section{Results}

We recruited a total of 672 trekkers in Lukla at $2860 \mathrm{~m}$ and retained 529 at $3400 \mathrm{~m}$ and 363 at $4300 \mathrm{~m}$. The others had incomplete data or were lost to follow-up. A similar proportion were lost to follow-up in the groups with vs without preexisting hypertension (30\% vs $21 \%$ at $3400 \mathrm{~m}$ $[P=0.05]$ and $45 \%$ and $58 \%$ at $4300 \mathrm{~m}[P=0.05])$.

Table 2 shows the demographic characteristics of unique participants with and without AMS at either altitude. Table 1 shows the proportions of participants with AMS at 3400 and $4300 \mathrm{~m}$. Ascent rate did not differ between participants with AMS and without AMS (Table 1). Of the 60 participants with preexisting hypertension, 50 were taking antihypertensive medications (Table 2) and 10 were not taking BP medications.

There was no relationship between AMS and measured BP values at any altitude (Table 1 and Figure 1). There was also no relationship between measured $\mathrm{BP}$ values and AMS severity as measured by LLS $(P=0.05$, data not shown). Mean BP did not differ between participants who were taking acetazolamide and those who were not ( $P=0.05$, data not shown). At $4300 \mathrm{~m}$, but not $3400 \mathrm{~m}$, participants with AMS had statistically lower oxygen saturations (Tables 1 and 3).

Participants without a medical history of hypertension had a higher frequency of AMS compared with participants with a history of preexisting hypertension at $3400 \mathrm{~m}$ (Figure 2 and Table 1; at 3400 m: odds ratio [OR] 6.1;
95\% CI $0.8-4 ; P=0.04)$, but this finding was not statistically significant at $4300 \mathrm{~m}$ (OR 4.8; 95\% CI $0.6-35$; $P=0.05$ ) (Table 1). A similar proportion in each group was taking acetazolamide (70 [11\%] without vs 9 [15\%] with preexisting hypertension; $P=0.5$ ) and ibuprofen (40 [7\%] without vs 3 [5\%] with preexisting hypertension; $P=0.7$ ). Two people with preexisting hypertension developed AMS, 1 at $3400 \mathrm{~m}$ who was not taking antihypertensive medication, and 1 at $4300 \mathrm{~m}$ who was taking a beta-blocker.

Overall, the proportion of participants taking acetazolamide was similar in those with and without AMS (Tables 1 and 2). A similar pattern was seen with ibuprofen use. We could not determine dosage of the medication or whether these medications were being taken prophylactically or therapeutically.

Results of the multivariate analysis to investigate the association between history of preexisting hypertension and measured BP values with AMS at either altitude, taking into account known risk factors, are given in Table 3. Male sex (OR $0.59 ; 95 \%$ CI $0.37-0.96 ; P=0.033$ ), history of hypertension (OR 0.16; 95\% CI 0.025-0.57; $P=0.016$ ), and higher $\mathrm{SpO}_{2}(\mathrm{OR} 0.93 ; 95 \%$ CI $0.87-0.98 ; P=0.011)$ were associated with lower odds ratio of AMS. Measured BP, BMI, and use of acetazolamide or ibuprofen were not associated with risk of AMS.

\section{Discussion}

In our large observational cohort of trekkers, AMS was common at $3400 \mathrm{~m}$ and $4300 \mathrm{~m}$. We found no relationship between the physiological variable of measured BP and AMS prevalence or severity. In fact, none of the physiological variables differed in a clinically meaningful way 
Table 2. Characteristics of study participants with and without acute mountain sickness

\begin{tabular}{|c|c|c|}
\hline & $\begin{array}{l}\text { No AMS } \\
(n=574)\end{array}$ & $\begin{array}{l}A M S \\
(n=98)\end{array}$ \\
\hline \multicolumn{3}{|l|}{ Sex, $n(\%)$} \\
\hline Male & $347(61)$ & $47(48)$ \\
\hline Female & $224(39)$ & $51(52)$ \\
\hline \multicolumn{3}{|c|}{ Anthropometrics, mean (95\% CI) } \\
\hline Height $(\mathrm{cm})$ & $173(173-174)$ & $172(170-174)$ \\
\hline Weight $(\mathrm{kg})$ & $72(71-73)$ & $71(68-74)$ \\
\hline $\operatorname{BMI}\left(\mathrm{kg} \cdot \mathrm{m}^{-2}\right)$ & $24.0(23.7-24.2)$ & $23.7(23.0-24.5)$ \\
\hline \multicolumn{3}{|c|}{ Athletic ability, n (\%) } \\
\hline Sedentary & $8(1)$ & $0(0)$ \\
\hline Average & $228(41)$ & $48(51)$ \\
\hline Athletic & $264(48)$ & $38(40)$ \\
\hline Very athletic & $53(10)$ & $9(9)$ \\
\hline \multicolumn{3}{|c|}{ Medical history, n (\%) } \\
\hline Prior AMS & $53(10)$ & $10(11)$ \\
\hline Hypertension & $58(10)$ & $2(2)$ \\
\hline Diabetes & $11(2)$ & $1(1)$ \\
\hline High cholesterol & $44(8)$ & $12(12)$ \\
\hline Asthma & $25(4)$ & $6(6)$ \\
\hline Migraines & $31(5)$ & $9(9)$ \\
\hline Heart disease & $14(2)$ & $0(0)$ \\
\hline Thyroid disease & $30(5)$ & $7(7)$ \\
\hline Smoking & $31(5)$ & $5(5)$ \\
\hline Prior hospitalization & $43(8)$ & $11(11)$ \\
\hline \multicolumn{3}{|c|}{ Medication types, n (\%) } \\
\hline Antihypertensives $^{\mathrm{a}}$ & $50(9)$ & $1(1)$ \\
\hline Diabetes & $6(1)$ & $0(0)$ \\
\hline Migraine & $9(2)$ & $3(3)$ \\
\hline Heart disease & $8(1)$ & $0(0)$ \\
\hline Thyroid disease & $25(4)$ & $8(8)$ \\
\hline Aspirin & $37(6)$ & $3(3)$ \\
\hline Acetazolamide & $69(12)$ & $11(11)$ \\
\hline Dexamethasone & $1(0.2)$ & $1(1)$ \\
\hline Acetaminophen & $11(2)$ & $3(3)$ \\
\hline Ibuprofen & $33(6)$ & $10(10)$ \\
\hline
\end{tabular}

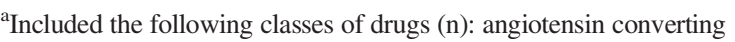
enzyme inhibitor/angiotensin receptor blocker (21), beta-blocker (3), calcium channel blocker (7), renin inhibitor (1), thiazide (1), 2 drug combination (11), 3 or more drug combinations (3), and unknown (3).

between participants with and without AMS. This highlights the lack of physiologic markers of this illness and the clinical nature of the diagnosis. Although our clinical experience suggests that travelers to high altitude worry about their BP causing symptoms of AMS, our data do not support this concern.

In contrast, we found that a history of preexisting hypertension was associated with a lower risk of AMS. The physiologic mechanism for this observation remains unclear, but regulation of CBF may play a role. At lowland elevations, control of CBF involves a complex interplay of pressure regulation by cerebral arterioles, coupling of blood flow to metabolism, and neurogenic regulation mediated by astrocytes and the endothelium. ${ }^{14}$ In hypertensive individuals, the hypertrophy of arteries and decreased production of the vasodilator nitric oxide results in lower baseline CBF. ${ }^{15}$ The hypoxic conditions of high altitude stress the homeostasis of CBF. The brain is exquisitely sensitive to hypoxia, so the hypoxemia drives increased ventilation, which results in hypocapnia. This results in opposing forces on blood vessel diameter because hypoxia has a dilatory effect, whereas hypocapnia has a constrictive effect. However, the vasodilator effect is dominant, resulting in an increase in CBF. ${ }^{16}$ Classically, AMS is thought to be due to cerebral vasogenic edema with increased CBF as the driving etiology. ${ }^{17}$ Supporting this hypothesis, 2 studies found that individuals that developed AMS were less able to regulate increased CBF than those that did not. ${ }^{18,19} \mathrm{It}$ is possible, therefore, that increased arterial thickness, decreased production of the vasodilator nitric oxide, and lower baseline $\mathrm{CBF}$ enable individuals with hypertension to more effectively buffer against a pathogenic increase in CBF.

Another possibility, perhaps even in conjunction with altered cerebral vascular hemodynamics, is that the medications taken by individuals with preexisting hypertension alter their susceptibility to AMS. Sympathetic activation and subsequent activation of the reninangiotensin-aldosterone system may contribute to the development of AMS. ${ }^{17,20}$ Thus, taking beta-blockers, angiotensin converting enzyme inhibitors, or angiotensin receptor blockers for hypertension theoretically could blunt the effects of these pathways in the development of AMS. Retrospective studies have shown that betablockers are not associated with increased or decreased risk of AMS, ${ }^{8,21}$ but whether angiotensin converting enzyme inhibitors and angiotensin receptor blockers influence AMS susceptibility has not been documented. Theoretically, both may affect susceptibility to AMS and other altitude-related illnesses such as high altitude pulmonary edema. ${ }^{22}$ This is clearly an area where further research is needed.

The proportion of trekkers with AMS in our study is lower than previously reported in this area of Nepal. ${ }^{23,24}$ This may be due to the proportion of participants taking prophylactic medications such as acetazolamide and ibuprofen, or it may be related to the ascent profile, which had little variation and reflected the recommended rate of ascent from guidelines ${ }^{25}$ because most of our participants were recruited from organized groups of travelers. We found no studies that have previously reported the prevalence of AMS in Namche Bazaar. More than $10 \%$ of participants had AMS at this relatively lower altitude, and this was similar to the proportion who reported AMS at $4300 \mathrm{~m}$. Given the high number of visitors to Namche Bazaar, this 
Panel A: 3400 m

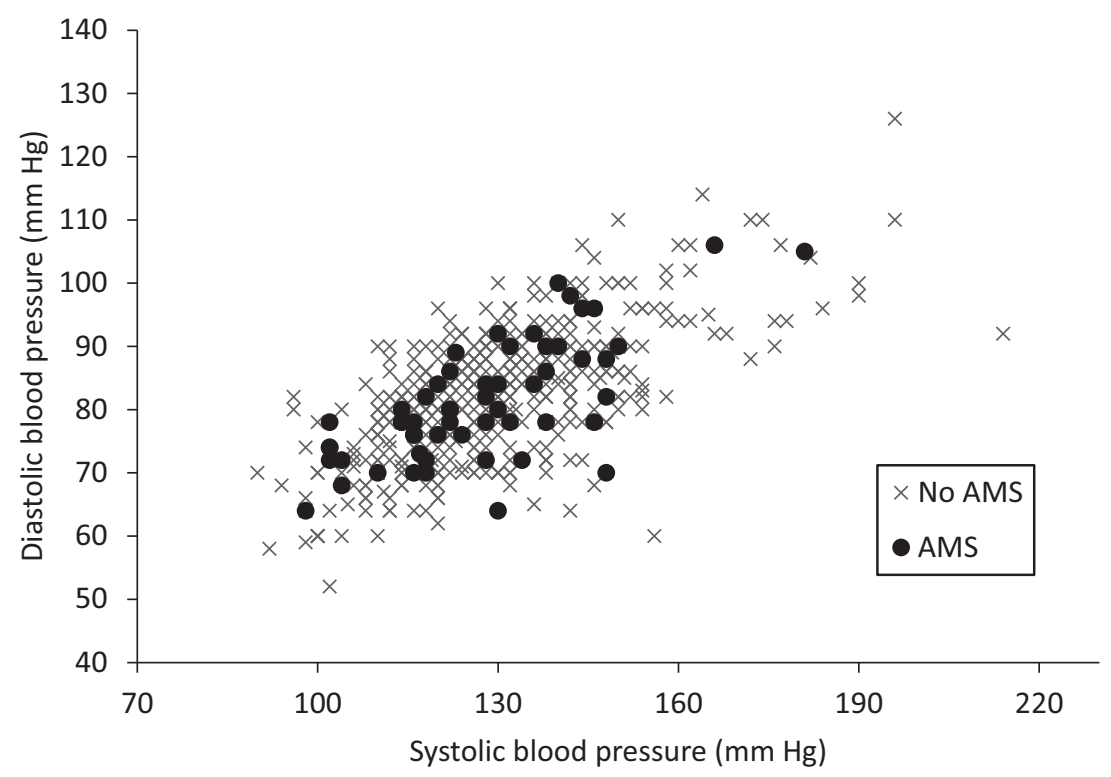

Panel B: 4300 m

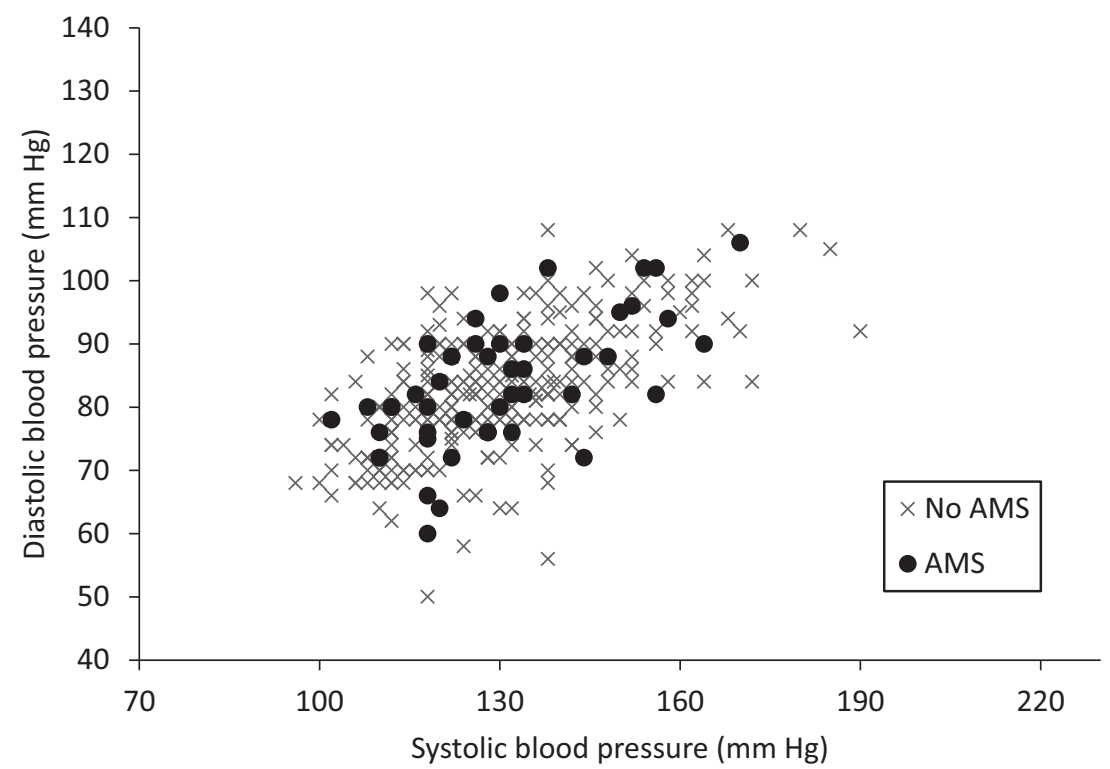

Figure 1. Individual participants' systolic blood pressure and diastolic blood pressures with $(\bullet)$ and without $(\times)$ acute mountain sickness at $3400 \mathrm{~m}(\mathrm{~A})$ and $4300 \mathrm{~m}(\mathrm{~B})$.

proportion translates into a large number of trekkers with AMS at this common tourist destination, where the burden of disease may not be adequately appreciated. These data are important for local provision of healthcare to trekkers. Also noteworthy is that the proportion of trekkers taking acetazolamide was the same in those with and without AMS. We cannot determine whether the medication was being taken prophylactically or for treatment; however, it may be that acetazolamide is not as effective in an uncontrolled setting as in controlled trials.

Our analyses included the commonly reported risk factors for AMS. In our study, male sex conferred a lower risk for AMS. Other studies have had disparate results about sex differences and AMS susceptibility. ${ }^{11,26-31}$ The reasons for these differing results are unclear. No value of BMI was found to be associated with increased 
Table 3. Results of multivariate analyses on outcome of acute mountain sickness at any altitude for all unique participants

\begin{tabular}{lll}
\hline Variable & OR $(95 \%$ CI $)$ & $\mathrm{P}$ \\
\hline Age & $1.00(0.98-1.02)$ & 0.87 \\
Male sex & $0.59(0.37-0.96)$ & $0.033^{\mathrm{a}}$ \\
History of HTN & $0.16(0.03-0.57)$ & $0.016^{\mathrm{a}}$ \\
Acetazolamide use & $0.96(0.45-1.92)$ & 0.91 \\
Ibuprofen use & $1.86(0.80-4.06)$ & 0.13 \\
$\mathrm{BMI}$ & $1.01(0.94-1.08)$ & 0.80 \\
$\mathrm{SpO}_{2}$ & $0.93(0.87-0.98)$ & $0.011^{\mathrm{a}}$ \\
$\mathrm{SBP}$ measured & $1.01(0.99-1.02)$ & 0.40 \\
\hline
\end{tabular}

${ }^{\mathrm{a}} P<0.05$.

risk of developing AMS in our cohort. Although several previous articles suggested higher BMI was a risk factor for AMS, ${ }^{11,13}$, other research is consistent with ours in that no association was found. ${ }^{12,29,31}$ Because BMI does not distinguish between lean muscle and fat and is simply a height to weight ratio, it cannot provide reliable information about fitness or other physiologic attributes related to acclimatization and therefore is unlikely to be an independent predictor of AMS susceptibility. Higher $\mathrm{SpO}_{2}$ was also associated with less AMS, but only at $4300 \mathrm{~m}$. The differences we observed in measured
$\mathrm{SpO}_{2}$ are small, however, and unlikely to be clinically significant.

Further research is warranted to determine whether the apparent protective effect of preexisting hypertension is reproducible in other populations and with different ascent profiles. In addition, work pursuing the physiologic basis for the inverse association between AMS and preexisting hypertension might further elucidate the mechanisms of AMS and identify new targets for treatment and prevention. Studies evaluating ambulatory and nocturnal BP may be particularly helpful and provide more accurate information about arterial pressure response to high altitude.

\section{LIMITATIONS}

As an observational cohort study, a number of factors may pose limitations. We enrolled a convenience sample, and this may have resulted in selection bias, wherein only healthy trekkers chose to participate; alternatively, less healthy people who wanted additional health monitoring during their trek may have been more likely to enroll. Because the past medical health information recorded in this study is self-reported, it is possible that participants' medical histories do not match their recollection and some

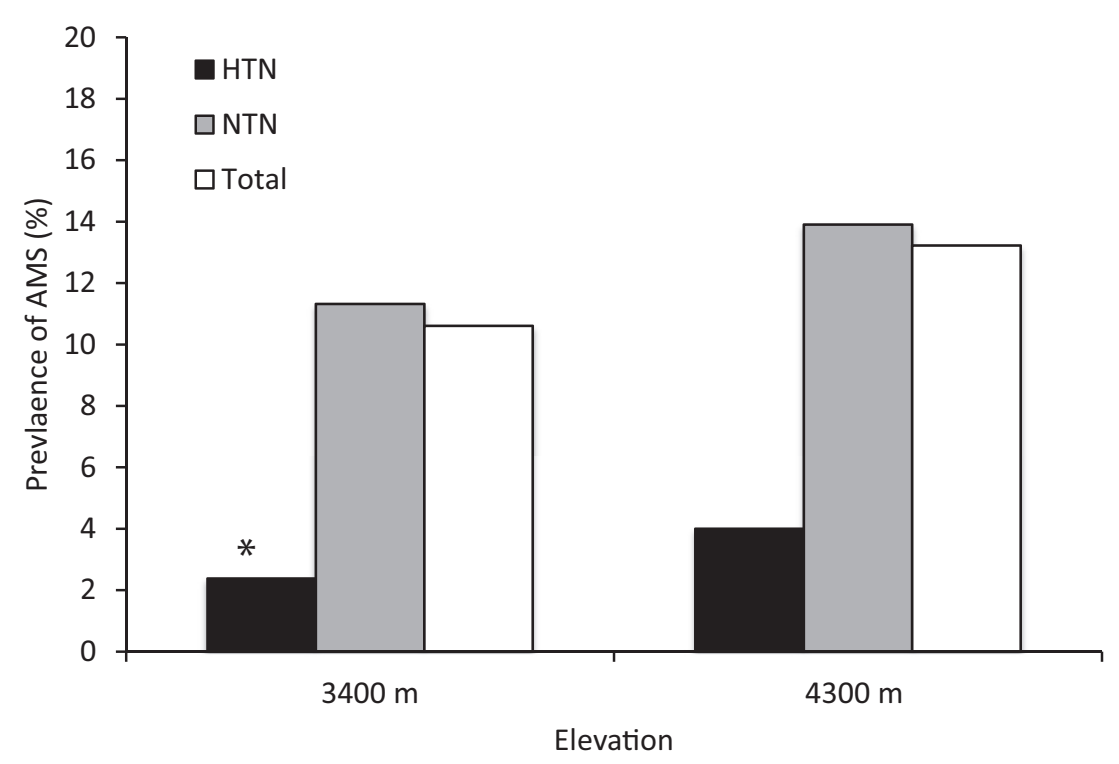

Figure 2. Percentage of participants with acute mountain sickness at $3400 \mathrm{~m}$ and $4300 \mathrm{~m}$ (total and in subgroups of those with preexisting hypertension and no history of hypertension). See Table 2 for numbers in each group. ${ }^{a} P=0.04$. 
participants with preexisting hypertension may have been misclassified. It is also possible that some participants identified themselves as having the chronic medical condition of hypertension, when in fact they do not. Participants enrolled were primarily English speaking, which may limit the generalizability of the findings.

Many participants were lost to follow-up during the study, especially at higher sites. We cannot exclude the possibility that sick trekkers were more likely to drop out. This would skew the data to include fewer patients who developed AMS, and our reported rates may be underestimates. The rate of drop-out was similar between those with and without preexisting hypertension. We cannot determine how more participants with AMS would influence our analyses of risks.

Because of the number of classes of antihypertensive medication taken and the small number of participants taking each class, we could not determine the relationship of specific classes of antihypertensive medicine and AMS. Medications were self-administered by participants, and many did not know their dosages. We also could not verify compliance with taking the listed medications. Other nonpharmaceutical agents such as caffeine and alcohol may have been used by participants to varying degrees, and it is not known how this may have affected our results, although usage likely was similar between groups, given the demographic similarities. Dietary options are fairly consistent throughout the Khumbu valley, and diet was unlikely to differ greatly between groups.

As an observational study, our results reflect the complicated "real world" situation that most high-altitude travelers experience. Given that we could not control participants' trekking experience, our data should be interpreted as hypothesis generating. Future controlled studies should verify our findings in hypobaric chamber studies or other controlled settings and compare groups based on BP medicine class and randomized use of acetazolamide and/or ibuprofen.

\section{Conclusions}

We found no relationship between measured $\mathrm{BP}$ values and AMS. However, our results suggest that the risk of AMS may be lower in people with a history of preexisting hypertension. This novel finding requires confirmation in future studies with larger numbers of participants with preexisting hypertension and with more detailed monitoring, such as with 24-h ambulatory BP. Although prevalence of AMS in our study was lower than previously reported in the Everest region, altitude illness remains an important concern for trekkers in Nepal, even at lower destinations such as Namche Bazaar.
Acknowledgments: The authors thank Buddha Basnyat for his involvement in the conception of the study and for providing additional funding and logistical support. Special thanks to the following people who helped with data collection: Bikash Basyal, Devlin K. Cole, Thomas Freeman, Jessica Gehner, Thomas Kim, Dana Levin, Luke F. Mather, Theodore McConnell, Catherine O'Leary, Purshotam Paudel, Alicia Peterson, Benoit Phelan, Nirajan Regmi, Brett Sorge, Katherine Stuart, Aditya Tiwari, David Twillman, Alex Whelan, and Jared Velgersdyk. The authors would also like to thank Peter Holck for preliminary data analysis not included in the present paper.

Author Contributions: Study concept and secured funding (LK); study design (LK, JS, SP); data collection (LK, TDS, SP, JS, MM, CD, AS, DY); statistical analysis (AT); wrote the first draft (CD, TDS, JS, LK); critical revision (LK, CD, AS, DY, TDS, MM, SP, AT); read and approved the final manuscript (all authors).

Financial/Material Support: This study received funding from the Wilderness Medical Society Hultgren Grant, supported by the Academy of Wilderness Medicine (C). Equipment was donated by Welch-Allyn.

Disclosures: None.

\section{References}

1. Keyes LE, Sallade TD, Duke C, Starling J, Sheets A, Pant S, et al. Blood pressure and altitude: an observational cohort study of hypertensive and nonhypertensive Himalayan Trekkers in Nepal. High Alt Med Biol. 2017;18(3):267-77.

2. Keyes LE, Mather L, Duke C, Regmi N, Phelan B, Pant S, et al. Older age, chronic medical conditions and polypharmacy in Himalayan trekkers in Nepal: an epidemiologic survey and case series. J Trav Med. 2016;23(6):taw052.

3. Faulhaber M, Gatterer H, Burtscher M. Preexisting cardiovascular diseases among high-altitude mountaineers in the Alps. J Travel Med. 2011;18(5):355-7.

4. Faulhaber M, Flatz M, Gatterer H, Schobersberger W, Burtscher M. Prevalence of cardiovascular diseases among alpine skiers and hikers in the Austrian Alps. High Alt Med Biol. 2007;8(3):245-52.

5. Luks AM. Should travelers with hypertension adjust their medications when traveling to high altitude? High Alt Med Biol. 2009; 10(1):11-5.

6. Honigman B, Theis MK, Koziol-McLain J, Roach R, Yip R, Houston C, et al. Acute mountain sickness in a general tourist population at moderate altitudes. Ann Intern Med. 1993;118(8):587-92.

7. Ledderhos C, Pongratz H, Exner J, Gens A, Roloff D, Honig A. Reduced tolerance of simulated altitude (4200 m) in young men with borderline hypertension. Aviat Space Environ Med. 2002;73(11):1063-6.

8. Winkler L, Lhuissier FJ, Richalet JP. Systemic blood pressure at exercise in hypoxia in hypertensive and normotensive patients. J Hypertens. 2017;35(12):2402-10.

9. von Elm E, Altman DG, Egger M, Pocock SJ, Gøtzsche PC, Vandenbroucke JP, et al. The strengthening the reporting of observational studies in epidemiology (STROBE) statement: guidelines for reporting observational studies. Int J Surg. 2014;12(12):1495-9.

10. Roach RC, Bärtsch P, Oelz O, Hackett PH. The Lake Louise acute mountain sickness scoring system. In: Sutton JR, Houston CS, Coates G, eds. Hypoxia and Molecular Medicine: Proceedings of the 8th International Hypoxia 
Symposium Held at Lake Louise, Canada. Burlington, VT: Queen City Press; 1993:272-4.

11. Kayser B. Acute mountain sickness in western tourists around the Thorong Pass $(5400 \mathrm{~m})$ in Nepal. J Wilderness Med. 1991;2(2):110-7.

12. Gaillard S, Dellasanta P, Loutan L, Kayser B. Awareness, prevalence, medication use, and risk factors of acute mountain sickness in tourists trekking around the Annapurnas in nepal: a 12-year follow-up. High Alt Med Biol. 2004;5(4): 410-9.

13. Karinen HM, Peltonen JE, Kähönen M, Tikkanen HO. Prediction of acute mountain sickness by monitoring arterial oxygen saturation during ascent. High Alt Med Biol. 2010;11(4):325-32.

14. Peterson EC, Wang Z, Britz G. Regulation of cerebral blood flow. Int J Vasc Med. 2011;2011:823525.

15. Pires PW, Dams Ramos CM, Matin N, Dorrance AM. The effects of hypertension on the cerebral circulation. Am J Physiol Heart Circ Physiol. 2013;304(12): H1598-614.

16. Willie CK, MacLeod DB, Smith KJ, Lewis NC, Foster GE, Ikeda K, et al. The contribution of arterial blood gases in cerebral blood flow regulation and fuel utilization in man at high altitude. J Cereb Blood Flow Metab. 2015;35(5):873-81.

17. Hackett PH, Roach RC. High-altitude illness. N Engl J Med. 2001;345(2):107-14.

18. Bailey DM, Evans KA, James PE, McEneny J, Young IS, Fall L, et al. Altered free radical metabolism in acute mountain sickness: implications for dynamic cerebral autoregulation and blood-brain barrier function. $J$ Physiol. 2009;587(1):73-85.

19. Van Osta A, Moraine JJ, Mélot C, Mairbäurl H, Maggiorini M, Naeije R. Effects of high altitude exposure on cerebral hemodynamics in normal subjects. Stroke. 2005;36(3):557-60.

20. Bärtsch P, Bailey DM. Acute mountain sickness and high altitude cerebral oedema. In: Swenson E, Bärtsch P, eds. High Altitude Human Adaptation to Hypoxia. New York, NY: Springer; 2014:379-404.
21. Keyes, LLF, Richalet, JP. Beta-blockers, hypertension and tolerance to high altitude. International Hypoxia Symposia. Lake Lousie, Canada. 2013.

22. Swenson ER. Ace inhibitors and high altitude. High Alt Med Biol. 2004;5(1):92-4.

23. Basnyat B, Savard GK, Zafren K. Trends in the workload of the two high altitude aid posts in the Nepal Himalayas. J Travel Med. 1999;6(4):217-22.

24. Basnyat B, Lemaster J, Litch JA. Everest or bust: a cross sectional, epidemiological study of acute mountain sickness at 4243 meters in the Himalayas. Aviat Space Environ Med. 1999; 70(9):867-73.

25. Luks AM, McIntosh SE, Grissom CK, Auerbach PS, Rodway GW, Schoene RB, et al. Wilderness medical society practice guidelines for the prevention and treatment of acute altitude illness: 2014 update. Wilderness Environ Med. 2014;25(4 Supp1):S4-14.

26. Bartsch P, Swenson ER. Clinical practice: acute high-altitude illnesses. N Engl J Med. 2013;368(24):2294-302.

27. Canoui-Poitrine F, Veerabudun K, Larmignat P, Letournel M, Bastuji-Garin S, Richalet JP. Risk prediction score for severe high altitude illness: a cohort study. PloS One. 2014;9(7), e100642.

28. McDevitt M, McIntosh SE, Rodway G, Peelay J, Adams DL, Kayser B. Risk determinants of acute mountain sickness in trekkers in the Nepali Himalaya: a 24-year follow-up. Wilderness Environ Med. 2014;25(2):152-9.

29. Wagner DR, Fargo JD, Parker D, Tatsugawa K, Young TA. Variables contributing to acute mountain sickness on the summit of Mt Whitney. Wilderness Environ Med. 2006;17(4): 221-8.

30. Beidleman BA, Tighiouart H, Schmid CH, Fulco CS, Muza SR. Predictive models of acute mountain sickness after rapid ascent to various altitudes. Med Sci Sports Exerc. 2013;45(4):792-800.

31. Ziaee V, Yunesian M, Ahmadinejad Z, Halabchi F, Kordi R, Alizadeh R, et al. Acute mountain sickness in Iranian trekkers around Mount Damavand $(5671 \mathrm{~m})$ in Iran. Wilderness Environ Med. 2003;14(4):214-9. 